Emilia Kledzik

UAM

emilia.kledzik@gmail.com
Data przesłania tekstu do redakcji: 19.05 .2014

Data przyjęcia tekstu do druku: 02.07.2014

\title{
Poetycki projekt Róžy Domašcyny między folklorem i nowoczesnością
}

Abstract: Kledzik Emilia, Poetycki projekt Róžy Domašcyny między folklorem i nowoczesnościa (Róža Domašcyna's Poetical Project between Folklore and Modernity). „Poznańskie Studia Slawistyczne" 8. Poznań 2015. Publishing House of the Poznań Society for the Advancement of the Arts and Sciences, pp. 67-82. ISSN 2084-3011.

Poetical project by Sorbian poet Róža Domašcyna fits into the category of „,minor literature”, coined by F. Guattari and G. Deleuze in 1975. Despite its inevitably political, ecological and ideological local connotations, it is rooted in the experience of modernity, still unpopular among the contemporary Sorbian writers. Its main topics are: the devastation of Lusatian environment, erotic and cultural hybridity. Domašcyna uses the hybrid nature of Sorbian identity to create an post-modern subject, conscious of the non-transparent nature of language. The result is an original poetry, which suits the current comparative and postcolonial categories of interpretation.

KeYwords: Róža Domašcyna; modernity; Sorbs; folklore; minor literature; hybridity

Kategoria literatury mniejszej, zastosowana w latach siedemdziesiątych XX wieku przez Félixa Guattariego i Gilles'a Deleuze'a do umiejscowienia twórczości Franza Kafki w porządku historycznoliterackim, stanowi poręczne narzędzie analizy spuścizny mniejszości narodowych i etnicznych (Guattari, Deleuze 1975). Odmienność tej twórczości, zdaniem francuskich postmodernistów, zawiera się w immanentnej polityczności, „zaangażowaniu”, egzekwowanych kosztem suwerennego głosu podmiotu, który - nawet wypowiadając się we własnym interesie - za sprawą specyficznie uwarunkowanej recepcji w obrębie wspólnoty i poza nią skazany jest na diagnozę kondycji świata, z którego pochodzi. Polityczność tę kształtują różnorakie konteksty: poczynając od recepcji „większościowych” trendów literackich, wobec których literatura mniejsza zawsze pozostaje „spóźniona”, poprzez odniesienia do aktualnej sytuacji danej wspólnoty mniejszościowej, jej liczebności, pozycji w obrębie społeczeństwa większościowego, na języku jako medium artystycznym 
skończywszy. Literatura mniejsza zawsze powstaje w środowisku wielojęzycznym, sam więc wybór kodu urasta do rangi deklaracji światopoglądowej. W zależności od stopnia zdystansowania autora do medium przekazu można jednak mówić o artystycznych „wygranych” i ,przegranych” tej polifoniczności: próba bowiem odnalezienia się pomiędzy językiem większości a językiem/językami mniejszościowymi może stać się źródłem kreacyjnego impulsu - szczególnie, jeśli przy okazji podważony zostaje referencjalny status języka w ogóle. Poezja mniejszości jest zatem specyficznym probierzem kondycji nowoczesnego podmiotu, który ma świadomość, że posługiwanie się językiem większości wiąże się z posiadaniem władzy, ale jednocześnie wyczuwa subwersywny potencjał, kryjący się w języku mniejszości, a ściślej - w napięciu rodzącym się pomiędzy tymi splecionymi ze sobą kodami. Język większości, nazywany dominującym, opresyjnym, kolonizującym, jest wszak również medium modernizacji, nowoczesności i kulturowej zmiany. Język mniejszości ma natomiast siłę konserwującą, zachowawczą. Estetyczna wartość, która rodzi się ze specyficznej dialogiczności, umyka literaturom narodowym, a odczytywana na ich tle, stanowi niepowtarzalne źródło wiedzy na temat kreacyjnego potencjału lokalności.

Sorabistka Christiana Piniekowa podjęła się charakterystyki literatury mniejszej na przykładzie literatury serbołużyckiej (Piniekowa 1998). W jej opinii twórczość tego typu, poza autorskim dylematem, w jakim języku pisać, charakteryzuje przewaga krótkich form gatunkowych (wierszy, nowel), brak zawodowych pisarzy, wreszcie: specyficzne warunki recepcji - dwujęzyczność nadawcy i odbiorcy. Koniec bilingwalności - przekonuje Piniekowa - oznacza koniec „małej literatury”; która ponosi odpowiedzialność za kulturową kondycję mniejszości. Napisany w roku 1998 tekst jest jednym z pierwszych naukowych głosów w obronie hybrydyczności kulturowej Łużyc. Antyesencjalistyczna deklaracja Piniekowej zbiegła się w czasie z brawurowym artystycznym projektem jednej z najpłodniejszych współczesnych serbołużyckich autorek Róžy Domašcyny, której twórczość zostanie w niniejszym artykule scharakteryzowana przez pryzmat dwóch pozornie opozycyjnych kategorii: folkloru i nowoczesności.

Walter Koschmal, ratyzboński sorabista, który odważył się przełamać monopol Serbołużyczan na pisanie o ich literaturze, w tomie dotyczącym perspektyw literatury serbołużyckiej po zjednoczeniu Niemiec, przytacza 
rozważania dwojga pisarzy drugiej połowy minionego stulecia: zmarłego w 2006 roku prozaika Jurija Brězana, autora największej jak dotąd liczby utworów w języku górnołużyckim i urodzonej w 1951 roku poetki Róžy Domašcyny. Oto jak Jurij Brězan wyłuszcza swój pogląd na literaturę, nieprzypadkowo zawarty w komentarzu dotyczącym specyfiki „małych narodów":

Ich historia nie jest historią wojen, bitew, wodzów i zdobywców, jest historią pisarzy, muzyków, malarzy, ludzi, którzy (...) mają dzieci, piszą dla nich bajki i piosenki; jest historią złożoną z historii zwykłych ludzi, na przykład dziadka mojego dziadka... Odpowiedzialność za taką świadomość historyczną ponosi przede wszystkim literatura. Mam przy tym na myśli nie literaturę historyczną, ale to, co z przeszłości czyni naturalną część współczesności, co słowa oznaczające strach i nadzieję wypełnia treścią wywodzącą się z naszej specyficznej historii (Brězan 1993: 65; przeł. E.K.).

Powyższa, jak mogłoby się wydawać, perspektywa kultury marginalnej, słabej, ma jednak poważne ograniczenia. Po pierwsze, obowiązkową wspólnotową aurę, jaką Brězan osnuwa wokół każdego serbołużyckiego aktu twórczego - czyni to zresztą nie tylko w wypowiedziach publicystycznych, a przede wszystkim w powieściach, opowiadaniach, także literaturze dziecięcej. Po drugie, choć taka literatura nie powinna szarżować rozmachem fabularnym, niewątpliwie może przytłaczać samych artystów, na których ciąży „odpowiedzialność za świadomość historyczną”. Kwestia postulowanego kodu tej twórczości także nabiera w niej niepośledniej wagi. Brězan stwarza pozór, że język serbołużycki jako medium zarezerwowane dla sfery domowej, prywatnej, intymnej, lepiej wyraża jakże dyskretne doświadczenie bycia „Innym”, autentyczniejszym, sobą, w oddaleniu od zawirowań Wielkiej Historii. Nie ma tu miejsca na kulturową i językową hybrydyczność; sfera serbołużyckiej dyskrecji i (w domyśle) niemieckiej niedyskrecji są od siebie wyraźnie oddzielone, by nie powiedzieć - nieprzekraczalne.

Róža Domašcyna, przedstawiając alternatywny wobec Brězanowskiego projekt literacki, także podkreśla pacyfistyczną perspektywę, z którą identyfikują się przedstawiciele tej mniejszości, ale akcentuje również inny punkt wyjścia, który obrać mogą pisarze serbołużyccy:

Szansą dla tej literatury jest posiadanie siły oddziaływania (...). Wybór języka nie ma tutaj znaczenia. Najgorsze, co może przytrafić się słowu pisanemu, jest brak zrozu- 
mienia, a co za tym idzie, niemożność jego zakwestionowania. To moje najgłębsze przekonanie, także przez wzgląd na język, w którym obecnie piszę (Domašcyna 1993: 78; przeł. E.K.).

Dictum komunikacyjne, na które decyduje się Domašcyna, wynika z przekonania, że zachowanie literatury pisanej po serbołużycku nie jest gwarancją przetrwania lokalnej kultury (Domašcyna 1993: 8-9). Opiewana po serbołużycku ,prowincja-twierdza” kojarzona bywa w literaturze schyłku XX wieku ze stopniowo zanikającą „oazą spokoju” (jak w powieściach Jurija Krawžy), która wymaga obrony (na przykład w Die Leute von Salow/Salowčenjo Jurija Brězana), a jej specyficzna idylliczność to recepta na zło otaczającego świata (w Krabacie II tego samego autora). Tymczasem, jak zauważają (co warto podkreślić) przede wszystkim nielokalni sorabiści, przełom polityczny i zjednoczenie Niemiec spowodowały, że granica między kulturą niemiecką a serbołużycką stała się jeszcze bardziej niestabilna i szanse na utrzymanie odrębności kulturowej zmalały niemal do zera (Barker 2006: 96). Szczególnie w teorii, choć także - jak pokazuje stanowisko i twórczość Róžy Domašcyny oraz kilkorga jej poprzedników, w tym Kito Lorenca - w poezji, następuje zmiana paradygmatu kulturowego. Model „Entweder - Oder” (albo - albo), postulujący dokonanie wyboru między niemieckością a łużyckością, strategia odgraniczania, są zastępowane przez wzorzec pluralistyczny „Sowohl - Als auch” (zarówno - jak i), strategię łączenia. Tej „,serbołużyckiej transgresyjności” nie znajdziemy w żadnym z utworów Jurija Brězana, natomiast w swoim projekcie nie tylko poetyckim, ale i tożsamościowym, ujmuje ją Róža Domašcyna (Dueck 2003), autorka sześciu tomików poetyckich, antologii serbskiej prozy, kilkudziesięciu opowiadań, trzech zbiorów bajek i legend łużyckich, albumów fotograficznych dotyczących Łużyc, w tym jednego poświęconego Serbołużyczankom, tłumaczka i redaktorka nieistniejącego już literackiego rocznika „Wuhladko”. Pisarka mieszka w Bautzen/ Budyšinie, kulturalnej stolicy Serbołużyczan, siedzibie Instytutu Serbołużyckiego i wydawnictwa Domowina. Urodziła się w 1951 roku w miejscowości Zerna/Sernjany, w tradycyjnej katolickiej rodzinie. Jej matka na co dzień nosiła tracht (łużycki strój ludowy). Domašcyna wybrała studia techniczne, została inżynierką w kopalni węgla brunatnego, o czym często i krytycznie pisze w wierszach. Na pomysł, by opublikować swoją twórczość, wpadła już w latach osiemdziesiątych XX wieku, ale jej pierwszy 
tomik ukazał się w 1990 roku, nosił tytuł Wróco ja doprědka du i w całości był napisany w języku górnołużyckim. Swoich niemieckojęzycznych utworów nie publikuje w Domowinie - co jest również symptomatyczne - ale w berlińskim wydawnictwie Gerharda Wolfa. Domašcyna rozwija projekt bilingwistycznych eksperymentów poetyckich, rezygnując z dotychczas uprawianej przez pisarzy równoległości pisania tekstów po niemiecku i serbołużycku lub zdeklarowanej monojęzyczności jej rówieśników. Mówi o nowoczesności i folklorze, o tym, co dzieje się między językami, co „ginie w tłumaczeniu”, eksploatuje unikalną przestrzeń estetyczną literatury mniejszej.

W nowoczesności literatury mniejszej, która - jak wspomniano powyżej za Guattarim i Deleuze'em - jest projektem niezbywalnie politycznym, nie może być mowy o geście całkowitego odrzucenia tradycji. Jeśli zatem przyjrzeć się serbołużyckiej literaturze z początków XX wieku, czasu działalności Jakuba Lorenca-Zalěskiego, okaże się, że w porównaniu $\mathrm{z}$ takimi manifestami nowoczesnego indywidualizmu, jak np. Kwiaty zła Charles'a Baudelaire'a, metody emancypacji podmiotu są tu zgoła inne: polegają na odpatetyzowaniu języka wspólnotowego, eksponowaniu modernistycznego konfliktu pomiędzy jednostką a zbiorowością, lecz wciąż zanurzone są w serbołużyckim folklorze. Ważnym kodem tekstowym pozostaje serbołużycka geopoetyka: opis wyidealizowanego krajobrazu naturalnego to pretekst do deklaracji uczuć patriotycznych. Serbołużycka nowoczesność i ponowoczesność rzadko bywają więc faktyczną dekonstrukcją wspólnotowego paradygmatu literatury mniejszej, który obserwujemy choćby w literaturze polskiej dwudziestolecia międzywojennego (cf. wiersze-manifesty skamandrytów), częściej - co podkreślają również sami sorabiści (Scholze 1998: 24-30) - recepcja nowoczesności pozostaje powierzchownym przeszczepieniem swoistych zabiegów estetycznych: nielinearnej narracji, eksperymentów z czasem i przestrzenią w powieści, zabiegów autotematycznych, uprawianiu „sztuki dla sztuki” etc. $\mathrm{Na}$ tę paradoksalną naturę rozważań o nowoczesności zwracał uwagę Michał Paweł Markowski, pisząc o ich podwójnej naturze: zachowawczej i krytycznej (Markowski 2007). Jeśli natomiast rozumieć nowoczesność nie tylko jako rewolucję formalną w literaturze, ale przede wszystkim jako postulat rewizji esencjalistycznych dyskursów tożsamościowych oraz tzw. silnego podmiotu, poezja Róžy Domašcyny jest pierwszym i jak dotąd 
niedoścignionym projektem w historii literatury serbołużyckiej. Nie oznacza to jednak, rzecz jasna, że poetka całkowicie porzuca trop wspólnotowy; przeciwnie - wzorem wielu pisarzy postkolonialnych postrzega swoją tożsamość jako immanentnie hybrydyczną i czyni ją przedmiotem swojej poetyckiej refleksji. Jeśli posłużyć się w tym miejscu znaną tezą Homiego Bhabhy o pedagogicznym i performatywnym wymiarze dyskursu narodowego/wspólnotowego (Bhabha 2010: 153), Domašcyna przesuwa akcent z pedagogiki na performance. W jej utworach pojawia się „turystyczna świadomość" człowieka żyjącego w (po)nowoczesności, objawiająca się dystansem wobec serbołużyckiego skansenu kulturowego. Podkreślam: poetka nie czyni tego z zamiarem całkowitej dekonstrukcji tożsamości wspólnoty, z której się wywodzi, ale przekonuje, że prawda o niej leży gdzie indziej - nie w inscenizowanej na potrzeby rynku turystycznego wspólnocie przednowoczesnej (chociaż i ta ją interesuje), ale w wypieranym przez stulecia kulturowym wymieszaniu, hybrydyzacji, wielojęzyczności i wielokulturowości mieszkańców tego regionu. Ponowoczesność jest epoką gloryfikującą tak definiowany regionalizm i jego komparatystyczny potencjał. Gayatri Chakravorty Spivak w przełomowej dla badań porównawczych, wydanej w 2003 roku, książce pod prowokacyjnym tytułem Death of a Discipline pisała o kryzysie utopii globalizacyjnej właśnie w kontekście renesansu kategorii regionu, który w nowoczesności utracił swój hermetyczny charakter enklawy, a stał się probierzem lokalności (Spivak 2003).

Christian Prunitsch zwraca uwagę, że dojrzały projekt poetycki Róžy Domašcyny rozwinął się na bazie typowego serbołużyckiego warsztatu poetyckiego: monojęzyczności, zabawy rymem i rytmem, tematyzowania lokalnego krajobrazu (Prunitsch 2001: 264 i n.). Można dodać, że powstałe w latach osiemdziesiątych XX wieku wiersze, opublikowane w pierwszym tomiku poetki, wpisują się w nurt krytyki cywilizacyjnej, charakterystycznej dla całej późnej literatury enerdowskiej. Ten największy rozdział w historii twórczości wschodnioniemieckiej Wolfgang Emmerich nazywa najbliższym europejskiej nowoczesności (Emmerich 2007: 239). Ich subwersywny charakter był dwojakiego rodzaju: formalnego, ale i światopoglądowego - przełamywanie reguł genologii szło w parze ze zdystansowaniem wobec ideologii. Krytyka systemu politycznego wymierzona była w socjalistyczny kult technologii, pozostającej na usługach zimnowojennych napięć, 
a więc w antyhumanistyczne i antyekologiczne dziedzictwo oświeceniowej racjonalności, która - jak pisał Günter Kunert w 1966 roku - doprowadziła do takich tragedii, jak Auschwitz i Hiroszima (Emmerich 2007: 275). Ta ocena cywilizacji zachodniej, zbieżna z tezami Theodora Adorna i Maxa Horkheimera z Dialektyki oświecenia, przetrwała przełom polityczny i stała się jednym z głównych argumentów w późniejszej debacie na temat tożsamości wschodnioniemieckiej i wartości literatury enerdowskiej.

„Ekologizm” pisarzy wschodnioniemieckich (Niedermeier 2002: 121) stał się specyficznym udziałem pisarzy serbołużyckich. Obszar Łużyc był rejonem Niemiec najsilniej dotkniętym dewastacją z powodu wydobycia węgla brunatnego. Działalność wydobywcza na tym terenie trwała wprawdzie od początku XX wieku, ale również w czasach NRD węgiel brunatny pozostawał podstawowym surowcem energetycznym i symboliczną gwarancją suwerenności państwa wschodnioniemieckiego (Kledzik 2013). Eksploatacja terenu zarówno przed, jak i po przełomie politycznym wiązała się nie tylko z opustoszałym, „księżycowym” krajobrazem powyrobiskowych jezior, o którym Wolfgang Hilbig pisze w poruszającym wierszu pt. das meer in sachsen (Hilbig 2008: 84). W związku z rozwojem przemysłu wydobywczego na Łużycach doszło także do zmiany struktury etnograficznej (tworzenie nowych osad dla ludności napływowej, w większości niemieckojęzycznej, wysiedlanie mieszkańców z osad położonych na terenie rozbudowy kopalni odkrywkowych). Od początku lat dwudziestych XX wieku z powierzchni ziemi zniknęło 78 wsi, a 13866 osób przesiedlono, z czego 72 osady i ponad 12 tysięcy ludzi między rokiem 1945 a 1989 (Förster 1993: 223 i n.). Najgłośniejsza stała się sprawa osady Horno, która trafiła na czarną listę w roku 1977, ostatecznie zaś wyburzono ją w 2004 roku mimo licznych protestów, w tym protestu pisarzy (Jurij Koch, Kito Lorenc, Jurij Brězan), którzy w 1987 roku stworzyli symboliczny łańcuch wokół jednej z maszyn wydobywczych (Niedermeier 2002: 120). Po zjednoczeniu Niemiec z powierzchni ziemi zniknęły częściowo osady: Trebendorf, Rohne, Scheife, Mülrose i Lakuma. Nic więc dziwnego, że poprzełomowa literatura serbołużycka podtrzymuje mit ekologicznej niszy, uruchamiając jednocześnie topos prowincjonalnego locus amoenus. U schyłku XX wieku pejzaż jest zarazem jednym z podstawowych rezerwuarów serbołużyckiej tożsamości narodowej i narzędziem ekologicznej krytyki antycywilizacyjnej. 
Oba te konteksty pojawiają się we wczesnej twórczości poetyckiej Róžy Domašcyny. W wierszu pt. Zeleny swět prezentuje klasyczny obraz kryjącej groby przodków przestrzeni-palimpsestu, przez którą przechodzi wspólnotowa axis mundi. Ten idylliczny krajobraz okazuje się jednak światem podrobionej naturalności: przeorana zieleń owocuje narastającą nad nią warstwą rdzy, po zielonej autostradzie jedzie się do apteki po zioła, w powietrzu unosi się zapach mentolowych papierosów, a elektroniczny dzięcioł jest zaledwie zielonkawy. Z kolei w utworze Wotkazanje postać z serbołużyckiej bajki, Šćipata Marhata, przegrywa walkę z nadciągającymi koparkami, które niszczą zamieszkałe przez nią dotąd wzgórze. I w tym wierszu poetka posługuje się konwencjonalnym repertuarem symbolicznym: Marhata trzyma w dłoni wrzos, jest ubrana w tradycyjny serbołużycki strój i próbuje zaklinać nieubłaganą rzeczywistość. Z końcowych wersów dowiadujemy się jednak, że Marhata zastygła w kamień na krawędzi jamy odkrywkowej, a silniki pompują z jej ciała krew. Modelowe zderzenie ludowości z nowoczesnością kończy się skamienieniem, klęską lokalnej kultury. W ton antycywilizacyjny uderza również poetka w wierszu pod sugestywnym tytułem Trawma (Trauma):

nan je pod štomom sydał před domom

huslował: Ach, moja hola... zemrěł

nana pochowali husle zahrjebali

bagry přijěli štom powalili dom wotbagrowali

nana wuhrjebali husle wuhrjebali

nan z rowa stanył husle wzał štom sadźił dom natwarił

bagry přijěli štom powalili dom wotbagrowali

nan zamrěł husle zawostajił

bagry přijěli husle złamali

nichtó njehuslował: Ach, moja hola...

ach mojahola achmojahola ach

bagry přijěli bagry hdźe nětk z nanom

hdźenětk achmojahola hdźenětkhdźenětk

achmojaholahdźenětkznanom (Domašcyna [s.a.]: 6-7).

W powyższym przykładzie poetycki koncept nie wyczerpuje się w proekologicznym manifeście. Christian Prunitsch słusznie zauważa, 
że Domašcyna raczej estetyzuje topiczny konflikt pomiędzy koparkami, symbolizującymi postęp technologiczny, katastrofę ekologiczną i brak poszanowania dla lokalnych tradycji, a ojcem, ludowym pieśniarzem, którego świat skazany jest na zniknięcie (Prunitsch 2001: 272). Serbołużycki pejzaż z jego stałymi elementami: progiem domu, pniem drzewa i skrzypcami, bardziej niż tematem manifestu staje się przedmiotem artystycznej gry z konwencją pieśni ludowej, co może sugerować diagnozę o podobnie konwencjonalnym jak folkowe metrum o charakterze opozycji pomiędzy serbołużycką prowincją a dewastującym je, technologicznie zaawansowanym, zewnętrzem. Jako krajobraz uwolniony od przymusu alegorii pozostaje więc zjawiskiem czysto językowym, pozbawionym referencji, mimetycznie nieczytelnym.

Osobnym tematem w poezji Domašcyny jest serbołużycka autofolkloryzacja, opisywana $\mathrm{z}$ ironią strategia konserwowania domniemanego tradycyjnego stylu życia i esencjonalistycznie pojmowana lokalna tożsamość. Proces zamykania słowiańskiej mniejszości w folklorystycznym skansenie znakomicie opisała sorabistka Elka Tschernokoshewa w książce Das Reine und das Vermischte, charakteryzując obraz Serbołużyczan w niemieckich gazetach (Tschernokoshewa 2000). W kontekście tezy Jürgena Habermasa, że terminologia sugeruje określony punkt widzenia, autorka prezentuje charakterystyczny stereotyp serbołużyckiej prowincji: Serbołużyczanie to naród żyjący w kontakcie z „naturą”, przeciwstawianą „,cywilizacji”, trudniący się rolnictwem, silnie przywiązany do nie zmieniającej się od wieków tradycji. Tschernokoshewa udowadnia, że taka charakterystyka mniejszości jest przykładem etykietowania - nie mającym uzasadnienia w empirii. Wskazuje na folklorystyczne rytuały, pokazuje, że na przykład słynna procesja wielkanocna tzw. Osterreiten w dzisiejszym kształcie obchodzona jest mniej więcej od początku XX wieku (nie jest zatem ,„pradawna”), a biorący w niej udział Serbołużyczanie, współcześnie rzadko trudnią się uprawą ziemi. W ten sposób powstaje zafałszowany obraz Innego, przypisujący mu określone role społeczne, najczęściej z dala od politycznego i społecznego centrum dzisiejszych Niemiec: należy go lokować (jako rolnika/chłopa) poza strukturą nowoczesnego społeczeństwa przemysłowego. Podobnie w dyskursie kulturowym - jak ocenia badaczka - Serbołużyczanom przypisuje się atrybuty autentyczności, jednorazowości, pierwotności, całościowości, podczas gdy dzisiejsza kultura charakteryzowana jest przez 
globalizację, powtórzenie, przyspieszenie, zerwanie etc. (Tschernokoshewa 2000: 60). Autorka podkreśla, że ów obraz nie jest jedynie wykładnią niemieckich stereotypów, ale także serbołużyckich autostereotypów. Mieszkańcy Łużyc pielęgnują swoją prowincjonalność: podkreślają niechęć do otwartych konfliktów, szacunek dla natury/przyrody (ekologizm), pasywność i apolityczność (Tschernokoshewa 2000: 100).

Wspomniana kulturowa „czystość” i ,przednowoczesność” występuje w wierszach Domašcyny w figurach serbołużyckich lalek oraz serbołużyckiego klauna w środkowoeuropejskiej klatce. Sonet Błótowski raj przynosi obraz tradycyjnej idylli, którą - w duchu omówionej powyżej krytyki antycywilizacyjnej - zakłócają dźwigi, zanieczyszczone rzeki i wydobywający się z komina tlenek siarki. A mimo to:

sej sprócnje za turistow lapu staja

hdyž čołmar ćěka do dźěła do raja

a něhdźe nošerjo kašć zahrjebaja (Domašcyna [s.a.]: 10)

kobieta wkłada na głowę czepiec „dla turystów”. Jeszcze sugestywniej prezentuje tę sytuację niemiecka strofa tego samego wiersza:

sie putzt sich für turisten, stellt sich aus

mit lapa wirkt der kopf exotisch doch

am fließ ein ansichtkartenparadies (Domašcyna 1991: 53).

Symulacja kultury jest w istocie demonstracją jej martwoty. Jak pisze Tschernokoshewa, nie chodzi o to, że ktoś zakłada strój ludowy, śpiewa ludową piosenkę czy tańczy ludowy taniec. „Pytanie o «folkloryzację» nie rozstrzyga się także w tym, czy ów folklor, który jest dziś uprawiany, pochodzi z «pierwszej», czy «drugiej» ręki (...). Nie sama praktyka, ale spojrzenie, w którym ludzie albo kultury zostają zredukowane do tego, co folklorystyczne, co jednocześnie oznacza, że są «wyobrażane» jako zacofane" (Tschernokoshewa 2000: 104). W wierszu Blótowske klanki pozornie jest mowa o reklamowanych przez sprzedawcę serbołużyckich lalkach ubranych w tradycyjne stroje. W rzeczywistości są to jednak Serbołużyczanki, których lalkowe piękno zmienia się w turystyczny towar, źródło zarobkowania. Folklor zostaje przeciwstawiony nowoczesności, a jednocześnie społeczeństwo, które go praktykuje, kategoryzowane jest jako słabiej rozwinięte, niecywilizowane, tradycyjne, łatwo poddające się zewnętrznej władzy. 
Tschernokoshewa konkluduje: tak rozumiana „folkloryzacja” mniejszości jest aktem wewnętrznej kolonizacji (Tschernokoshewa 2000: 105).

Nie tylko jednak refleksja nad serbołużyckością jako konstruktem kulturowym i związana z nią krytyka esencjalizmu czyni z Domašcyny poetkę nowoczesności. Drwinę z turystycznej symulacji uzupełniają zawarte w późniejszych tomikach autorki Zwischen gangbein und springbein (1995) i Selbstredend, selbstzweit, selbstdritt (1998) rozważania o chwiejnej naturze podmiotu w związku z niestabilną naturą jego Imienia. Domašcyna nie poprzestaje więc na diagnozie nieautentyczności - „skamieniałym" rzecznikom folkloru chce przeciwstawić własną hybrydyczność, dwujęzyczność, międzykulturowość. Stawia się więc w sytuacji słowiańskiego subalterna, którego nazwisko jest stereotypowo trudne do wymówienia, a problemy artykulacyjne przeradzają się w problemy tożsamościowe. W cyklu Triangel regional poetka deklaruje ,ja tu nie pasuję/ przynależę", estetyzując postrzeganą z punktu widzenia kultury większościowej inność, rozumianą jako obcość, wykluczenie. W fizjonomicznej autoprezentacji ,ja" mówiącego pobrzmiewa echo teorii ras:

Ich gehöre nicht wirklich dazu

diese kschtschrschkombination in meinem namen

hat man hier nicht

und habe ich nicht auch schrägstehende augen

eine etwas verlängerte nase

ein fliehendes

kinn

ich könnte mich freilich

Häusler Hausmann Hauser nennen

dann wären die augen wie sie sein sollen

oder ich könnte mich ausschließlich

Keschroschasch nennen

dann wäre die schrägstellung wie sie sein muss... (Domašcyna 1998: 74).

Innym wierszem tożsamościowym $\mathrm{z}$ tomu Zwischen gangbein und springbein jest utwór pod znaczącym tytułem $J a$, w którym Christian Prunitsch dostrzega zarys charakterystycznego dla autorki projektu ,polisemicznego ciała" (Prunitsch 2001: 282-283):

außerhalb der sprachlosigkeit der totalen

verstummung der totalen hörigkeit

wetz ich mir gangbein und springbein 
aus dem stand komm ich sag mir laß mich

nicht mal tot sein wenn ich gestorben bin (Domašcyna 1995: 4).

Wiersz ma charakter programowy, zważywszy na pojawiające się sformułowania gangbein i springbein, które znalazły się również w tytule tomu. Pierwszy poruszany w nim problem dotyczy kwestii językowych: żywiołem, z którego wywodzi się mówiące ,ja”, jest brak języka, totalne milczenie i totalna słyszalność. Stagnacja, skostniałość, skamielina - metafora pojawiająca się we wcześniejszych tekstach pisarki - jest jednak wyłącznie punktem wyjścia, własnością otaczającego świata, ale nie jej samej. Ona porusza się krokiem balansującym pomiędzy „nogą idącą” a „nogą skaczącą”, jest w ciągłym ruchu. Ten nieistniejący, bo zawieszony, a jednak dynamiczny moment, w innych kontekstach poetyckich nazywa poetka szpagatem. Nasuwa on na myśl rozdarcie pomiędzy dwoma systemami językowymi i dwoma modelami kultury. Poza projektem językowym, który z milczenia prowadzi ją do logorei, w powyższym wierszu ukryty jest również projekt filozoficzny: rodząca się z heterogenizmu kulturowego dynamika to gwarancja nieśmiertelności, antidotum na przemijalność, ale i autorska sygnatura w tekście poetyckim. W nowoczesnym europejskim projekcie literackim gwarancją utraconej pisarskiej oryginalności był autotematyzm, przekształcający - np. w wierszach Mirona Białoszewskiego - akt poetyckiej kreacji w zabawę, karnawał, żonglerkę słowami, za którą kryła się artystyczna świadomość. Podobnie jest u Domašcyny: jej wiersze są barokowe, eksperymentalne, autotematyczne i oddające relacyjną naturę języka. Poetka niczego nie boi się tak, jak utraty głosu, cisza jest dla niej równoznaczna ze śmiercią. Wiersz Wendisch przynosi wizję odwróconej afazji:

wendisch ist gestorben sagst du mir und speist

die worte mir ins gesicht daß es stumm wird

und silbe um silbe verschluckt die kinder

reden nur noch in zeichen (Domašcyna 1995: 37).

Pretekstem do tworzenia poezji, podobnie jak w cyklu Triangel regional znów staje się stereotyp, diagnoza kondycji kultury większościowej, której przedstawiciele od stuleci obwieszczają śmierć języka, a zatem i kultury serbołużyckiej. , Ja” mówiące ,połyka” złowieszczo brzmiące sylaby i choć ono samo zachowuje milczenie, dzieci mówią ,jeszcze tylko" 
znakami - spełniają więc podstawowy warunek aktu komunikacji i posługują się kodem symbolicznym. Akt karmienia przedstawicielki mniejszości serbołużyckiej dekonstruuje ostateczność tezy ,język serbołużycki jest martwy", staje się pożywką dla jego paradoksalnego wzrostu.

Konceptem, na którego bazie Domašcyna najchętniej buduje swoje poetyckie projekty, jest artystyczny potencjał, rodzący się z nieprzystawalności kodów językowych i kulturowych. Jak wspomniałam powyżej, autorka demonstruje swoją metalingwistyczną świadomość, a jednocześnie uwikłanie w oba dyskursy: folklorystyczny styl poezji serbołużyckiej, wraz z repertuarem tematów, toposów, figur słów i myśli, oraz nowoczesną formułę poetycką: $\mathrm{z}$ wierszem wolnym, luźnym podejściem do rymów (choć twórczyni nie stroni również od sonetów), niestabilnością poetyckiego ,ja” oraz podstawowymi tematami nowoczesności: relacji pomiędzy człowiekiem a naturą, erotyką i demaskatorskim charakterem mowy poetyckiej.

Ostatni wiersz, o którym chciałabym wspomnieć w kontekście projektu nowoczesności w poezji Róžy Domašcyny, to utwór często zauważany przez krytyków. Jego omówienie znaleźć można zarówno we wspomnianej książce Christiana Prunitscha, jak i w artykule Cheryl Dueck (2003). Stanowi on kwintesencję artyzmu poetki i najlepszą znaną mi egzemplifikację jej koncepcji hybrydycznego podmiotu, wyraziście kontrastującą z wykreowanym autentyzmem serbołużyckiego folkloru. Pochodzi z tomu Selbstredend, selbstzweit, selbsdritt, który już w tytule ustawia problem tożsamości w perspektywie komunikacyjnej - monologu, rozmowy lub właśnie: polilogu? Jedno jest pewne: przesłanie Domašcyny pojawia się nie expressis verbis, ale pomiędzy słowami, kategoriami gramatycznymi, skryptami kulturowymi - jest świadectwem wymieszania, hybrydyczności.

die sprache verröchelt
ich benenne noch einmal die dinge
im bilderbuch wie am anfang: swontschko
die sonne gelegt in den wasser der flüssin nebenher
die füchsin die zugleich fuchs ist

und starka die gänsin

zischelt mir zu

hutschko soj

das macht gänsehaut meiner köpfin 
daß meine mündin

nur noch das geräusch des gähnens weiß

frag nicht warum und wieso

endet eine sprache

jede sprache verendet mit einem menschen

doch wenn du ihm nachahmst läßt du ihn

auferstehen in deiner person

was wichtig ob er noch lebt -

und trachtenteile wie uniformsteile

sind sowieso aus dem gleichen nest

aber wortflötz ist erdflötz

ist das liegende und das hangende

an überhängen und bruchsstellen

nistet die füchsin

sag huuuutschko soooj

und się fängen zu gähnen an

alle gänse

alle (Domašcyna 1998: 9).

Wiersz mówi o ziszczonym czarnym scenariuszu, dotyczącym zanikania języka serbołużyckiego: mowa „rzęzi”, a podmiot liryczny na nowo dokonuje nazwania-kreacji elementów świata. Zaczyna od znanego już sielskiego krajobrazu: widnieje na nim słowiańskie słoneczko, rzeka i lisica, która jest jednocześnie lisem. W drugiej strofie pojawia się gęś, która syczy, ale nie ma wrogich intencji. Jej doświadczenie jest raczej bliźniacze wobec doświadczenia podmiotu, który używa syczącej, równie niezrozumiałej co język zwierząt, słowiańskiej mowy. Używając ludowej frazy hutschko soj, którą - jeśli wierzyć komentarzom odautorskim - stosuje się na Łużycach przy karmieniu gęsi (ma powodować efekt ziewania) (Domašcyna 1999: 9), czyni z podmiotu swoją komunikacyjną partnerkę. I chociaż tekst mówi o „znikaniu” języka, jest dosłownym rejestrowaniem jego rozpadu, w istocie daje obietnicę przetrwania - w rodzaju gramatycznym, konotującym słowiański skrypt kulturowy i w - jak nazwalibyśmy ją z dzisiejszej perspektywy metodologicznej - pamięci posthumanistycznej, mowie „dozwierzęcej”, ludowych neologizmach. Nawet słowo śmierć, które w języku niemieckim jest rodzaju męskiego, zyskuje słowiańską, żeńską konotację, co obezwładnia jego omnipotentny charakter, podważa referencjalność. W wierszu pojawiają się także inne rodzajowe neologizmy: 
lisica, gęś, rzeka - niczym ślady serbołużyckości w języku dominującym. Najważniejsza wydaje się jednak refleksja podmiotu, dotycząca indywidualistycznego wymiaru języka: „każda mowa kończy się razem z człowiekiem" - tu także Domašcyna pozostaje poetką odżegnującą się od wszelkich wspólnotowych deklaracji. Język umiera razem z posługującym się nim podmiotem. Szansą na jego trwałość jest naśladowanie, które może jednak krępować niczym zuniformizowany strój ludowy. Zamiast bezrefleksyjnego kopiowania, proponuje poetka metaforę warstwowości języka, którą pięknie egzemplifikuje niemiecko-serbołużyckimi neologizmami. To w językowych pęknięciach - pisze - gnieździ się lisica; to hutschko soj ma moc sprawczą. Taki jest kreacyjny potencjał jej literatury mniejszej, powstającej nie w izolacji, ale w kulturowych szczelinach, warstwach i palimpsestach. Uchwycona w poetyckim eksperymencie różnica pomiędzy mimikrą a parodią stwarza możliwość gry znaczeniem w nieskończonym procesie semiozy (Prunitsch 2001: 285), który nie ulega utopii wspólnej, odideologizowanej mowy. W ten sposób udaje się Domašcynie zrealizować nowoczesny postulat wieloznaczności bez obaw, że żywioł niemiecki zdominuje, zgasi, zaciemni element serbołużycki. Po wyeliminowaniu pojęcia czystości i zastąpieniu jej kategorią ambiwalencji w odniesieniu do wzajemnej relacji obu dyskursów ich przenikanie prowadzi do - dyskretnego - wzbogacenia, nie zubożenia poetyckich sensów.

\section{Literatura}

Barker P., 2006, „, The pain of a dying species” or ,the new waters” of a bicultural literature: Sorbian literature since 1990, „Neohelicon” nr 2, s. 91-103.

Bhabha H., 2010, Miejsca kultury, przeł. T. Dobrogoszcz, Kraków.

Brězan J., 1993, „,Die Enge is sanktioniert”. Fragen von Hans-Peter Hoelscher Obremeier, w: Perspektiven sorbischer Literatur, red. W. Koschmal, Köln, s. 51-68.

Domašcyna R., 1991, Zaungucker. Gedichte. Texte, Berlin.

Domašcyna R., 1993, Den Rückzug vor uns alle Wege offen, w: Perspektiven sorbischer Literatur, red. W. Koschmal, Köln, s. 69-78.

Domašcyna R., 1998, Zwischen gangbein und springbein. Gedichte. Zeichnungen von Maja Nadel. 2. Auflage, Berlin.

Domašcyna R., 1999, Selbstredend, selbstzweit, selbstdritt, Berlin.

Dueck Ch., 2003, Selbstredend selbzweit selbdritt: Serpentine Selves in the Poetry of Róža Domašcyna, „Canadian Slavonic Papers” nr 4, s. 283-294. 
Emmerich W., 2007, Kleine Literaturgeschichte der DDR, Berlin.

Erb E., 1991, Durch lauter gleich Frühnebeln schleiernde Hüllen. Laudatio auf Kito Lorenc, „Neue Deutsche Literatur” z. 6, s. 131-139.

Förster F., 1993, Ethnosoziale Aspekte der Siedlungsdevastation im Lausitzer Braunkohlenrevier (1924-1993). Rheinisches Jahrbuch für Kulturgrenzen und nationale Identität, red. H.L. Fox, Bonn.

Guattari F., Deleuze G., 1975, Kafka: Toward a Minor Literature, przeł. D. Polan, Minneapolis.

Hilbig W., 2008, Gedichte. Werke, Frankfurt am Main.

Kledzik E., 2013, Prowincjonalizowanie. Twórczość Jurija Brězana, Wolfganga Hilbiga i Andrzeja Stasiuka w perspektywie postkolonialnej, Poznań.

Koschmal W., 1995, Grundzüge sorbischer Kultur. Eine typologische Betrachtung, Bautzen.

Koschmal W., 1993, Perspektiven sorbischer Literatur, Köln.

Lazarus N., 2013, Kosmopolityzm a lokalność w literaturze światowej, przeł. D. Kołodziejczyk, „Porównania” nr 2, s. 29-46.

Lorenc K., 1999, Die Insel schluckt das Meer, „Zeitschrift für slawische Philologie” nr 2, s. 409-422.

Lorenc K., 1981, Serbska čitanka, Leipzig.

Markowski M.P., 2007, Polska literatura nowoczesna. Leśmian, Schulz, Witkacy, Kraków.

Niedermeier, M., 2002, Von Kulturbund bis „,̈kofaschismus”. Natur- und Landschaftzerstörung als Thema von Autoren der späten DDR, Ökologie und Literatur, red. P. Morris-Keitel, M. Niedemeier, New York.

Piniekowa Ch., 1998, Kleinliteratur - Versuch einer Begriffbestimmung am Beispiel sorbischer Literatur, „Lětopis” nr 1, s. 3-11.

Prunitsch Ch., 2001, Sorbische Lyrik der 20. Jahrhunderts, Bautzen.

Róža Domašcyna. Seria: Serbska poezija, [s.a.], red. Ch. Prunitsch, Budyšin.

Scholze D., 1998, Postmoderne tendency w serbskej literaturje? Jurja Brězanowej romanaj wo Krabaće (1976; 1994/95), „Letopis” nr 1, s. 24-30.

Spivak G.Ch., 2003, Death of a Discipline, New York.

Tschernokoshewa E., 2000, Das Reine und das Vermischte. Die deutschsprachige Presse über Andere und Anderssein am Beispiel der Sorben, Münster. 